Geopolítica(s) Revista de estudios sobre espacio y poder ISSN: 2172-3958

\title{
A preeminência na América do Sul como fundamento da política externa brasileira entre 1945 e $1964^{1}$
}

\author{
André Nassim de Saboya ${ }^{2}$
}

Recibido: 22 de abril de 2016 / Aceptado: 21 de octubre de 2016

Resumo. A política externa brasileira entre o fim do Estado Novo e o Golpe de 1964 é caracterizada, em grande medida, pelo desenvolvimentismo e a busca pela industrialização do país. Analistas desse processo geralmente focam-se no aspecto econômico e nos interesses das elites civis, enquanto a busca por poder e preeminência é pouco ressaltada. Desse modo, um dos principais objetivos dos Estados na arena internacional é ignorado. O desenvolvimento econômico e industrial não deve ser considerado um fim em si mesmo, visto que o progresso material serve a determinado objetivo, que, para o Estado, é o aumento do poder. Este artigo busca retomar a geopolítica como um dos fundamentos para a política externa e para o desenvolvimento brasileiros no século XX, levando-se em conta a teoria pioneira de Mario Travassos, voltada para a preeminência na América do Sul, e a história da política externa brasileira ao longo da República Nova (1945-1964).

Palavras-chave: política externa brasileira; geopolítica; República Nova; Mario Travassos; América do Sul.

\section{[en] The Primacy in South America as basis for Brazilian Foreign Policy between 1945-1964}

\begin{abstract}
The Brazilian foreign policy between the end of the Estado Novo and the 1964 Coup d'état is characterized, to a large extent, by developmentalism and by the pursuit of industrialization. Analysts of this process usually focus on the economic aspect and on the civil elites' interests, while the search for power and primacy is often downplayed. Thus, one of the main objectives of the State in the international stage is overlooked. The economic and industrial development should not be considered an end in itself, since material progress is useful to reach a specified goal, that, to the State, is the increase in power. This article seeks to re-examine geopolitics as a fundamental tenet of Brazil's foreign policy and economic development in the 20th century, taking into account the pioneer theory of Mario Travassos, dedicated on South American primacy, and the history of Brazilian foreign policy during the Fourth Republic (1945-1964).
\end{abstract}

Keywords: Brazilian foreign policy; geopolitics; Fourth Republic; Mario Travassos; South America.

1 Esse artigo é parcialmente baseado na pesquisa realizada para minha dissertação de mestrado, A projeção continental do Brasil vis-à-vis o poder americano: competição e integração na América do Sul. Universidade Federal do Rio de Janeiro, 2015.

2 Pesquisador na Escola Nacional de Saúde Pública-Fundação Oswaldo Cruz.

E-mail: andresaboya@gmail.com 


\section{[es] La primacía en América del Sur como fundamento de la política exterior brasileña entre 1945 y 1964}

Resumen. La política exterior brasileña entre el final del Estado Novo y el Golpe de 1964 se caracteriza, en buena medida, por el desarrollismo y la busca de la industrialización de país. Los analistas de ese proceso generalmente se centran en el aspecto económico y en los intereses de las élites civiles, mientras que está poco resaltado lo referente a la búsqueda de poder y primacía. De ese modo, uno de los principales objetivos de los Estados en la arena internacional es ignorado. El desarrollismo económico e industrial no debe ser considerado un fin en sí mismo, visto que el progreso material sirve a determinado objetivo, que, para el Estado, es el aumento de poder. Este artículo busca retomar la geopolítica como uno de los fundamentos de la política exterior y de desarrollo brasileña en el siglo XX, teniendo en cuenta la teoría pionera de Mario Travassos, centrada en la búsqueda de la primacía en América del Sur, y la historia de la política exterior brasileña a lo largo de la República Nova (19451964).

Palabras clave: política exterior brasileña; geopolítica; República Nova; Mario Travassos; América del Sur.

Sumario. 1. Introdução. 1. O pensamento de Mario Travassos. 2. O Brasil entre 1945-1964. 2.1. O governo Dutra. 2.2. O governo Vargas. 2.3. O governo Kubitschek. 2.4. Os governos Quadros e Goulart. Conclusão. Referências Bibliográficas.

Cómo citar: Saboya, André Nassim de (2016) “A preeminência na América do Sul como fundamento da política externa brasileira entre 1945 e 1964”. Geopolítica(s). Revista de estudios sobre espacio y poder, vol. 7, núm. 2, 277-300.

\section{Introdução}

O Brasil desenvolveu-se sobremaneira ao longo da República Liberal (1945-1964). Nesse período, a política externa manteve-se coerente com o processo interno de crescimento econômico, voltando-se prioritariamente para o desenvolvimento como um de seus objetivos. Assim, os países desenvolvidos figuravam como os principais parceiros do país à época, como fonte de recursos ou como mercado consumidor, em detrimento dos países periféricos.

A busca por desenvolvimento, no entanto, não é suficiente para explicar o papel secundário da América do Sul na política externa brasileira do período. Dentro e fora do Itamaraty, a Cepal e o Iseb apontavam para os benefícios de uma maior aproximação com os países da região e, particularmente, com a Argentina, como ferramenta para o aumento do desenvolvimento nacional, ao passo que os processos de rápido crescimento econômico e industrialização deveriam servir como poderoso incentivo para os países da região tentarem se aproximar do Brasil. Contudo, as iniciativas no período foram reticentes. O esboço de uma coordenação mais efetiva com a Argentina por meio dos Acordos de Uruguaiana, por exemplo, foi rapidamente lesado nos anos seguintes.

Neste artigo, argumenta-se como hipótese que a disputa com a Argentina por preeminência na América do Sul foi fundamental para o baixo nível de coordenação regional e que o modelo de desenvolvimento perseguido pelo Brasil, ao diminuir a influência argentina na região, prejudicava o entendimento entre os dois países e, como consequência, a cooperação em todo o subcontinente. 
As desconfianças geopolíticas entre o Brasil e a Argentina por vezes são ressaltadas na literatura que trata sobre a política externa da Ditadura Militar (19641985) (Teixeira da Silva, 2014; Gonçalves \& Miyamoto, 1993; Mello, 1997). Ao se analisar somente a República Liberal, objetiva-se enfatizar que as disputas geopolíticas entre Brasil e Argentina podem servir como chave de leitura para entender o relacionamento bilateral e as dinâmicas regionais também em períodos democráti$\cos$.

Assim, esse artigo tem como objetivo realizar uma pequena contribuição para o entendimento da política externa brasileira entre 1945 e 1964, caracterizada pelo desenvolvimentismo, a partir de considerações de ordem geopolítica.

Como esforço de síntese, o artigo está embasado na teoria de Mario Travassos ${ }^{3}$ para delimitar os contingenciamentos geopolíticos enfrentados pelo Brasil durante o período. A partir das considerações de Travassos, as linhas de atuação da política externa brasileira ao longo da República Liberal serão ressaltadas.

O artigo não se propõe a estabelecer uma causalidade, no entanto, entre o pensamento de Travassos e ação externa brasileira, mas, sim, em realçar os limites geopolíticos traçados por Travassos como fundamento de política externa. Assim, o artigo possui caráter descritivo, com atenção mais detalhada às relações do Brasil com a Argentina e com os Estados Unidos e ao esforço de desenvolvimento com aumento da projeção brasileira na América do Sul. Na conclusão, as disputas entre Brasil e Argentina serão avaliadas como fatores relevantes para a falta de coordenação e cooperação na América do Sul no período.

\section{O pensamento de Mario Travassos}

Na obra Projeção continental do Brasil (1947), Mario Travassos discorre sobre os imperativos geopolíticos da América do Sul que devem constar nos cálculos para a inserção internacional do país. Publicado primeiramente em 1930, sob o título de Aspectos geográficos sul-americanos, a obra de Mario Travassos apresentava recomendações quanto à gestão territorial brasileira e à ação externa no seu entorno regional, as quais providenciariam a projeção sobre a América do Sul. Na quarta edição, publicada em $1947^{4}$, a obra conta ainda no apêndice com artigos complementares escritos pelo autor.

O estudo da geopolítica, para Travassos, refere-se à identificação das possibilidades e dos obstáculos ao aumento de influência do Estado em dado território.

No quadro das ações humanas, os Estados nacionais tenderiam a buscar três objetivos na sua relação com o espaço: a de possuir várias saídas para o mar, a de dominar a totalidade das bacias hidrográficas e a de estender seu domínio para onde o tráfego os possibilite. As três tendências expressam o mesmo fenômeno, a procura pela expansão do poder em bases territoriais. Poder, nesse sentido, expressa-se como o controle e a influência sobre um território

Travassos identifica dois antagonismos naturais na América do Sul. O primeiro é o antagonismo entre os oceanos Atlântico e Pacífico, separados pela Cordilheira

3 Travassos escreveu um dos primeiros estudos sobre geopolítica no Brasil, ainda na década de 1930, foi o primeiro comandante da AMAN e influenciou os principais geopolíticos brasileiros (Vieira, 2008).

$4 \quad$ Este artigo faz referência à obra de 1947. 
dos Andes; o segundo é o antagonismo entre as bacias platina e amazônica, separadas pelo planalto boliviano, o centro da América do Sul. Os antagonismos geográficos geram instabilidades geográficas decorrentes das diversas formações estatais presentes na América do Sul.

O segundo antagonismo, entre as bacias amazônica e platina, revela-se mais central para a obra de Travassos. Apresentava-se, à época, como uma disputa em aberto, em que a bacia platina encontrava-se em vantagem devido à ação do Estado argentino. A parte central da obra reside em como neutralizar a ação argentina e aumentar a influência brasileira no continente, por meio de uma aproximação com a Bolívia ${ }^{5}$. A instabilidade entre a Brasil e Argentina por preeminência sobre a Bolívia seria a disputa característica do século XX, segundo as previsões de Travassos.

A Argentina havia dado os passos iniciais para influenciar de modo decisivo a Bolívia e, indiretamente, o Paraguai (um prolongamento do território boliviano), até alcançar o Peru, onde poderia estender sua influência até o Pacífico e a Amazônia. A forma como a Argentina conquistou essa preeminência deriva de sua política de comunicações e de sua rede ferroviária. Travassos percebeu que a Argentina estendeu sua possibilidade de tráfego para além da extensão da bacia do Prata, por meio da construção de ferrovias que aumentaram a centralidade do porto de Buenos Aires, de modo centrípeto sob o entorno regional. A política de comunicações argentina possibilitou um aumento dos investimentos argentinos nesses países mediterrâneos e andinos. Ademais, as ferrovias argentinas também aumentaram as possibilidades de comunicação com o Oceano Pacífico, a Argentina, a Bolívia e o Paraguai a portos chilenos e peruanos.

A Argentina usou o desenvolvimento derivado da economia agroexportadora para a realização desses empreendimentos, que favoreciam a economia argentina ao garantir renda derivada dos serviços do porto e de comunicações. O desenvolvimento seria um meio para potencializar a projeção internacional do país.

No caso brasileiro, Travassos reconhece a necessidade de se neutralizar a ação argentina por meio de uma aproximação com a Bolívia, aproveitando-se tanto da vertente amazônica quanto da vertente platina.

$\mathrm{O}$ autor desenhou um esquema de comunicações no Brasil platino e no Brasil amazônico de modo a neutralizar a Argentina. No caso do Brasil platino, a extensão da ferrovia noroeste até Corumbá e a construção de uma via até Foz do Iguaçu, complementar-se-iam por meio do aproveitamento dos Portos de Santos, Paranaguá, São Francisco, Porto Alegre e Rio Grande. No caso amazônico, seu potencial é manifesto pelas suas condições naturais, sem a necessidade de empreendimentos tão expressivos quanto os propostos no caso do Brasil platino. Ao Sul, o Rio Madeira alcança o planalto boliviano, com a possibilidade ainda de influenciar o território transandino.

O potencial amazônico, no entanto, era comprometido pelas suas condições naturais e pela baixa densidade demográfica, de modo que uma política decisiva naquela região seria mais viável por meio do estabelecimento de populações capazes de dar prosseguimento às vias de comunicação com os países vizinhos.

5 A Bolívia representaria uma espécie de Heartland do continente sul-americano, aos moldes da proposta por Halford Mackinder (1904). 
Travassos enfatizava que o Brasil detinha maiores condições de integrar a América do Sul do que a Argentina, extremamente dependente do porto de Buenos Aires. Travassos argumenta que a posição brasileira na América do Sul, com o controle da foz do Rio Amazonas e com o maior litoral, e seu tamanho dentro da região, fortalecem a ação brasileira no continente, de modo que Travassos também se remete aos conceitos de "espaço" (raum) e "posição" (lage) de Friedrich Ratzel (1897).

Travassos, nesse sentido, contrapõe-se ao pensamento de Carlos Badia Malagrida. Malagrida também foi teórico geopolítico e pensava na integração da América do Sul; contudo, considerava o tamanho e a diversidade brasileiros como óbices para o Brasil conseguir se impor na região. Malagrida, em El factor geográfico en la política sudamericana (1919), defende a criação de grandes federações sulamericanas, em substituição aos pequenos Estados, e subordinadas a uma supernação hispano-americana, sob o comando da Espanha - Malagrida era espanhol e foi cônsul na América Latina - com amplo comércio entre os países dessa comunidade hispano-americana. Malagrida enfatiza a integração dos países americanos como solução para o isolamento espanhol e para os conflitos dos países americanos. Para tanto, as federações deveriam se agrupar de acordo com o critério de regiões naturais. Desse modo, a Argentina, Estado mais desenvolvido e aberto ao comércio, deveria promover a integração dos países do antigo Vice-Reino do Prata - Argentina, Uruguai, Paraguai e parte da Bolívia - o que é uma possibilidade rechaçada e temida por Travassos.

Provavelmente, as definições de regiões da América do Sul de Malagrida e o objetivo de integrar a região tenham sido usadas por Travassos (Martins, 2011), no entanto, este busca contrapor-se às ideias daquele.

Além da Argentina, Travassos dava atenção especial à potência norteamericana. A influência estadunidense no mundo era indiscutível, segundo Travassos, devido à importância das relações econômicas e financeiras — não havia como contestar o poder americano-. Por meio do Mar das Antilhas e do Panamá, os Estados Unidos poderiam penetrar em direção à Amazônia e à Bolívia, o centro continental. O interesse americano pelos hidrocarbonetos, localizados nos países andinos e caribenhos, demonstrariam a penetração pelo norte do continente, conquanto o autor considerasse que os maiores progressos estadunidenses seriam alcançados pelo Pacífico, devido às abertas andinas e ao fracionamento político.

A projeção continental do Brasil em direção à Bolívia teria o papel de conter a influência estadunidense para a América do Sul. Nesse sentido, constata-se pela obra uma rivalidade incipiente entre Brasil e Estados Unidos, dado o movimento duplo e contrário em direção ao centro do continente sul-americano.

A perspectiva continentalista de Travassos, com a integração servindo como contrapeso aos Estados Unidos, também é encontrada em Malagrida, porém, para este, a integração seria encabeçada pela Espanha e pela Argentina (Malagrida, 1919). Nesse sentido, tanto Malagrida quanto Travassos inovaram ao pensar a integração continental, em um momento no qual a América Latina era pensada como uma região periférica na geopolítica (Cairo, 2008).

Do mesmo modo, Malagrida e, principalmente, Travassos também se contrapõem à visão da América do Sul voltada quase unicamente para o abastecimento dos grandes centros do mundo como defendido por Storni (2009 [1916]). Storni era almirante argentino e pensava na centralidade estratégica do comércio marítimo 
com a Europa via porto de Buenos Aires, ao transportar a riqueza do hinterland argentino, e dava pouca importância à integração continental. A centralidade do porto de Buenos Aires, segundo Travassos, era amplificada pela ação do Estado argentino, mas poderia ser contrabalanceada por uma ação decisiva dos planos de comunicação brasileiros, em benefício dos portos brasileiros do Sul e Sudeste e da calha amazônica.

A obra de Travassos influenciara a maioria dos geopolíticos brasileiros nas décadas seguintes. Segundo Scenna (1975), "[s]em dúvida o livro foi lido e relido por quem devia lê-lo e de certa forma passou a ser o pilar teórico sobre o qual se levanta o Brasil de nossos dias". Entre aqueles influenciados pelo pensamento travassiano estão Juarez Távora, Lysias Rodrigues e Golbery do Couto e Silva (Mello, 1997: 88-142). Os três concordaram, em grande medida, com os pontos de conflito no continente e com a necessidade de integração física, mas somaram outras considerações.

Távora (1954), comandante da Escola Superior de Guerra na década de 1950, argumentava que um dos objetivos permanentes do Brasil era a obtenção da hegemonia no continente sul-americano. Para alcançar esse objetivo, dever-se-ia perseguir o acúmulo material e tecnológico, em consonância com o pensamento de Travassos.

Rodrigues (1947), também militar e pensador geopolítico, atuante na década de 1950, no contexto de Guerra Fria, argumenta que a aliança com os Estados Unidos seria a forma de se conter a ameaça argentina e de se consubstanciar o poder brasileiro sobre a América do Sul.

Couto e Silva (1967), que seria um dos principais teóricos da Doutrina de Segurança Nacional, enfatiza o binômio segurança e desenvolvimento e argumenta a favor da aliança com os Estados Unidos não somente como forma de garantir a projeção do Brasil sobre o continente sul-americano como para providenciar ao país o controle sobre o Atlântico Sul. Couto e Silva, assim, expõe a tese do "aliado preferencial" em relação aos Estados Unidos, a partir do qual o Brasil poderia exercer o cerco contra Argentina e expandir para o Atlântico Sul como contrapartida ao esforço de defesa contra a subversão (Mello, 1997: 257-270).

Saraiva (2012: 33-35) defende que os estudos geopolíticos brasileiros, a começar pelos estudos de Travassos, influenciaram o pensamento político brasileiro a partir da década de 1930, para conter a influência argentina e promover as conexões viárias com a Bolívia. Góes Monteiro, chefe do Estado Maior do exército, também foi influenciado por esse pensamento e destacava, em cartas para o presidente Vargas, a necessidade de se modernizar o equipamento militar e de se preparar para uma guerra contra a Argentina. Segundo Martins (2011), o pensamento geopolítico de Travassos também teria influenciado Vargas a construir uma ferrovia ligando a cidade fronteiriça de Corumbá à Santa Cruz de la Sierra e a promover a Marcha para o Oeste, esforço de colonização do oeste brasileiro, promovido pelo Estado na década de 1930, - empenho esse que continuaria nas décadas seguintes-. O expansionismo brasileiro ao oeste, voltado para a contenção da Argentina, foi considerado como um dos objetivos da política externa brasileira no século XX, segundo Shilling (1981) e Chiavenato (1981).

As teses geopolíticas de Travassos, assim como de Távora, Rodrigues e Couto e Silva, enfatizavam a Argentina como principal desafio geopolítico do Brasil, e in- 
fluenciou as forças armadas brasileiras a concentrarem as tropas na fronteira sul do país, até pelo a década de 1970 (Saraiva, 2012: 39-47).

Os argentinos também nutririam desconfianças com relação ao Brasil. Como destacam Russel \& Tokatlian (2003), com o fim da Segunda Guerra Mundial, as desconfianças com a expansão brasileira e seu papel como "país-chave" dos Estados Unidos nutriam a lógica de rivalidade geopolítica. As preocupações geopolíticas argentinas, difundidas entre militares argentinos, remetem-se em grande medida aos objetivos de reintegrar os países do antigo Vice-Reino do Prata, conter o Brasil e alcançar a hegemonia na América do Sul (Russell \& Tokatlian, 2003; Guglialmelli, 1978).

Travassos estabelece três diretrizes para a atuação do Estado brasileiro. Primeiramente, a necessidade de contenção da Argentina, com expansão da influência brasileira sobre os países platinos e amazônicos por meio de obras de comunicação. Segundo, aumento da ocupação do interior brasileiro tanto para ampliar a área de atuação do litoral atlântico quanto para aumentar o potencial amazônico brasileiro. Terceiro, não confrontação com os Estados Unidos, mas preparação para uma rivalidade futura.

A estratégia brasileira de desenvolvimento, por meio de um programa de industrialização pesada e de aliança com os Estados Unidos, como advogavam Rodrigues e Couto e Silva, seria a maneira de alcançar os objetivos geopolíticos traçados por Travassos.

O pensamento de Travassos, portanto, situa os constrangimentos geopolíticos que enfrentaria o Brasil para tornar-se hegemônico na América do Sul; em particular, o desafio da ascendência argentina. O plano traçado por Travassos seria, em menor ou maior medida, seguido ao longo do período de 1945 a 1964 (Vieira, 2008).

Como se enfatizou na introdução, não se propõe estabelecer uma causalidade entre o pensamento de Travassos e a conduta da política externa brasileira no período, mas demonstrar que os constrangimentos geopolíticos estiveram presentes nos anos seguintes, à medida que ação governamental progredia em direção à ocupação do interior brasileiro.

\section{O Brasil entre 1945-1964}

\subsection{O governo Dutra}

O fim do Estado Novo (1937-1945) mudou a política brasileira e iniciou um novo período democrático. Houve continuidade, no entanto, com relação ao processo de industrialização por substituição de importações, iniciada de forma consistente ainda em 1930 (Furtado, 2005), à urbanização e ao prestígio das Forças Armadas, adquiridas com a participação na Revolução de 1930, no Estado Novo e na Segunda Guerra Mundial (Carvalho, 2005).

O governo de Eurico Dutra representou a continuidade da política de aproximação com os Estados Unidos na política externa brasileira. Na configuração da Guerra Fria do final da década de 1940 e começo da de 1950, o governo brasileiro posicionou-se decisivamente ao lado dos EUA na busca de ganhos econômicos e políticos, como ocorrera durante a Segunda Guerra Mundial (Moura, 1991: 59). 
Entre os exemplos dessa aproximação, destacam-se o engajamento para a assinatura do Tratado Interamericano de Assistência Recíproca (TIAR), em 1947, a criação da Organização dos Estados Americanos (OEA), em 1948, a fundação da Escola Superior de Guerra (ESG), em 1949, com base na doutrina formulada pelo National War College, no âmbito político-militar, e, no âmbito econômico, a liberalização dos fluxos de capitais em conformidade com as determinações dos acordos de Bretton Woods de 1944, ainda que países como o Reino Unido não tivessem realizado o mesmo procedimento.

A postura brasileira contrastaria com a política externa defendida por Juan Domingo Perón, que ascendeu ao poder argentino também em 1946. Nacionalista, Perón defendia a Tercera Posición como paradigma de política externa, rejeitando um alinhamento com os EUA ou com a URSS. O neutralismo, a busca de construção de um eixo de poder e de entendimento entre o Brasil e a Argentina que fosse capaz de projetar o poder de ambos na América do Sul, a política de nacionalizações e protecionismo, a resistência em incorporar-se às instituições de Bretton Woods e a política de estabelecimentos de tratados bilaterais iam contra o liberalismo norteamericano e à ideia de solidariedade hemisférica concebida pelos EUA. A Terceira Posição tinha sentido não somente político como econômico, dado o interesse argentino em diversificar o destino de suas exportações, especialmente em um momento de relativo declínio do seu tradicional parceiro comercial, a Inglaterra (Rapoport, 2000: 446-460).

Dutra mantinha a prudência com relação à Argentina. O comércio bilateral era importante, e o Brasil buscava manter as exportações de têxteis para o mercado argentino enquanto o trigo argentino supria bem o mercado brasileiro, especialmente em momentos de escassez nos outros centros de produção. Não havia, economicamente, motivos para a rivalidade entre Brasil e Argentina, visto que a produção de ambos os países se complementavam e tendiam ao crescimento bilateral.

A ideologia justicialista e as iniciativas econômicas de Perón para a América Latina eram vistas como uma ameaça aos interesses geopolíticos brasileiros na região. A busca de preeminência no Paraguai, convulsionado pela Guerra Civil (1947), ou o projeto de Perón por uma união econômica e política na América do Sul, tendo como eixo dinâmico a cooperação entre Argentina, Brasil e Chile (Pacto $\mathrm{ABC}$ ), eram interpretados com desconfiança pela diplomacia brasileira (Doratioto, 2014: 120-126).

Nesse contexto, o Brasil firmaria em 1948 com o Paraguai acordo para regular as atividades de cooperação militar prestadas por Missão Militar de Instrução, o qual representaria um fator relevante de influência política brasileira sobre aquele país. O presidente Alfredo Strossner, que governaria o país de 1954 a 1989, e que promoveu aproximação com o Brasil durante seu mandato, também recebeu treinamento de oficiais brasileiros (Souto, 2014).

Os primeiros dois anos de mandato de Dutra foram marcados por uma queda nas reservas monetárias brasileiras, com o aumento das importações, impulsionadas pelo câmbio valorizado, e por um sentimento de frustação com relação aos resultados da Missão Abbink ${ }^{6}$ e à baixa preocupação dos Estados Unidos com as

6 A missão, liderada por Walter Abbink, consistia na realização de estudos para verificar os gargalos da economia brasileira. O que o governo brasileiro acreditava ser uma série de medidas com envolvimento direto dos 
questões de desenvolvimento no Brasil ${ }^{7}$. O país começou a impor controles quantitativos de importação, priorizando as importações de maquinário em detrimento dos bens de consumo não-duráveis, e aprofundando a industrialização. Apesar dessa insatisfação com os Estados Unidos e da complementariedade com a Argentina, não houve maiores gestões para aproximação bilateral até o final do governo Dutra.

A ascendência brasileira no país mediterrâneo guarani e as desconfianças com relação à Argentina confirmam a tendência percebida por Travassos, a qual seria aprofundada nos anos seguintes, de tensão bilateral devido a fatores geopolíticos (Moniz Bandeira, 2010; Mello, 2001).

\subsection{O governo Vargas}

O governo Vargas coincidiria com a segunda metade do governo peronista (194655). Apesar de Vargas e Perón terem construído um legado político sobre a valorização dos trabalhadores ${ }^{8}$, a relação entre Brasil e Argentina no período do segundo mandato de Vargas ${ }^{9}$ não foi muito cordial.

Perón mantinha a proposta de criação do Pacto $\mathrm{ABC}$, o que era rejeitado pelo Itamaraty, encabeçado pelo ministro João Neves da Fontoura (o mesmo de Dutra) e, depois, por Vicente Rao. Ambos eram favoráveis à aproximação com os Estados Unidos e contrários à aliança com a Argentina ou com o peronismo. A proposta de um consórcio com o vizinho platino somente fortalecia a oposição interna ao presidente brasileiro, pois o congresso e a imprensa brasileiros eram em geral críticos a Perón, apresentando-o como uma ameaça ideológica, econômica e militar ${ }^{10}$. Perón também identificava um dos óbices à aproximação bilateral no Itamaraty, o qual fomentava a inimizade geopolítica entre os dois países devido a alguma excrescência imperial (Russell \& Tokatlian, 2003; Moniz Bandeira, 2010: 260).

As forças armadas brasileiras, por sua vez, também nutriam a rivalidade com a Argentina. Góes Monteiro, que desde a década de 1930 identificava a Argentina como maior ameaça ao Brasil, voltou a exercer a chefia do Estado-maior do Exército entre 1951-52. Monteiro recusava-se a cooperar com a Argentina por um plano de defesa do Atlântico Sul, sob o argumento de resguardar o pan-americanismo. De fato, uma aproximação militar com a neutralista Argentina era vista como uma ameaça à perspectiva de cooperação militar com os Estados Unidos (Moniz Bandeira, 2010: 254-262). A ameaça argentina, como teorizada por Travassos, manterse-ia como padrão entre os militares brasileiros e influenciaria as atitudes de política externa brasileira na República Nova.

Estados Unidos, como financiamento, consistiu em um conjunto de propostas liberais, para atrair investimentos externos em áreas estratégicas.

7 O Brasil, desde 1947, apoiava a criação da Comissão Econômica para a América Latina (CEPAL), que se debruçaria sobre os problemas econômicos da América Latina, em especial a industrialização. A pesar das resistências de países desenvolvidos, mesmo dos EUA, a CEPAL começou suas atividades em 1949.

8 Para mais sobre Vargas e trabalhismo, ver Gomes (1994).

9 Letícia Pinheiro nota que outros governos latino-americanos de cortes ideológicos parecidos poderiam convergir nesse propósito, como o do Chile, de Carlos Ibañez, a Bolívia, de Paz Estensorro, e o Equador, de Velasco Ibarra. Ver: Pinheiro (2013).

10 Perón aumentava as compras de armamentos, o que gerava desconfiança por parte de militares brasileiros, ver Rapoport (2000: 351-360). 
A iniciativa de aproximação de Perón para o Brasil não era isolada, o presidente argentino também buscou a diversificação das relações comerciais com outros países da América Latina ${ }^{11}$, como por meio da Ata de Santiago, com o Chile, além do apoio à integração gradual da América Latina, no âmbito da Cepal. Sem o apoio brasileiro, porém, os tratados comerciais não avançaram para uma união econômica. Em contraposição aos esforços de Perón, o Brasil buscou estreitar relações com outros países da região como o Peru, o Paraguai, a Bolívia, a Venezuela, a Colômbia e o Chile (Rapoport, 2000: 354-355). Verifica-se, portanto, que, ao invés de somar esforços para uma atuação coordenada, os países disputavam por maior influência regional.

Com relação aos Estados Unidos, o governo Vargas manteve a postura dos anos anteriores, em busca de mais benefícios da parceira com os norte-americanos. A partir de 1951, começou a funcionar a Comissão Mista Brasil-Estados Unidos (CMBEU), que, similar à Missão Abbink, possuía a incumbência de determinar gargalos que impediam o desenvolvimento brasileiro e propor soluções. A CMBEU encerrou suas atividades em 1953 com poucos resultados práticos à época, a não ser pela criação Banco Nacional de Desenvolvimento Econômico (BNDE). Vargas também seguiu o alinhamento na esfera político-militar, como se verifica pela assinatura de acordo de cooperação militar com os Estados Unidos em 1952, em que se aplicava a troca de equipamentos militares dos estadunidenses por areias monazíticas brasileiras e outros minerais estratégicos, e pelo voto a favor, no âmbito da OEA, ao combate do governo reformista guatemalteco, comandado por Jacobo Arbenz ${ }^{12}$ (Hirst, 2006; Cervo \& Bueno, 2002).

$\mathrm{O}$ apoio aos Estados Unidos encontrou um limite nas negociações sobre o envio de tropas brasileiras à Guerra da Coreia. O governo brasileiro evadia-se de responder aos pedidos de envio de soldados, procurando manter essa possibilidade como barganha em prol de mais investimentos na indústria de refinamento de petróleo, de processamento dos minerais estratégicos e de pesquisa em energia nuclear. Os EUA, porém, teriam diversas formas de coagir o Brasil, seja como fonte de financiamento, seja como principal destino das exportações de café ou como detentor virtualmente único da tecnologia nuclear, restringindo a cooperação nuclear entre países ocidentais (Moniz Bandeira, 2010: 323-354; Hirst, 2006).

$\mathrm{Na}$ esfera econômica, Vargas adotou medidas crescentemente nacionalistas, especialmente a partir do fim da CMBEU e do pouco avanço nas negociações com os EUA para a promoção da industrialização brasileira. Destacam-se a expedição da instrução 70 da Superintendência da Moeda e do Crédito (SUMOC), que estimulou a industrialização por substituição de importações, ao adotar o confisco cambial ${ }^{13} \mathrm{e}$

11 Em 1953, a Argentina estabelece Atos de União Econômica com o Chile, com o Paraguai e com o Equador, além de sugerir na Cepal a criação de uma união aduaneira latino-americana. Em 1954, celebra união econômica com a Bolívia.

12 À época houve outros casos de deposições de governos em prol de setores conservadores, como no Peru e na Venezuela, 1948, e em Cuba, 1952.

13 Pela medida, adotar-se-ia o sistema de taxas múltiplas de câmbio. Importações consideradas não essenciais seriam acrescidas taxadas por um ágio enquanto importações estratégicas para o esforço de industrialização seriam estimuladas por um deságio. Ao passo que as exportações de café, ainda significativas, receberiam um valor menor que as demais exportações, o que estimularia a diversificação dos investimentos produtivos. Ver: Giambiagi (2011: 12-15). 
a criação da Petrobras como $100 \%$ estata $1^{14}$ e responsável pela execução do monopólio do petróleo nacional. Além disso, Vargas ainda buscou aumentar sua base de apoio entre os trabalhadores, aprovando uma elevação de 100\% do salário mínimo.

A imprensa nacional era, em geral, contrária à figura de Vargas. As críticas contra o presidente, considerado autoritário e corrupto, avolumaram-se e ganharam o apoio de parte das Forças Armadas, que ecoavam as denúncias da UDN (partido conservador de oposição). Ademais, as medidas nacionalistas afiguravam-se contrárias a interesses das elites econômicas, em parceria com grupos internacionais (Moniz Bandeira, 2010: 261-262). Com o aumento das pressões pela renúncia do presidente, em particular dos militares, Vargas resolveu por uma medida drástica e suicidou-se no Palácio do Catete em 1954.

Perón também era questionado na Argentina. A política de fomento à industrialização afastou-a da Grã-Bretanha, sua principal compradora e fonte de investimentos. A Argentina passava desde o começo da década de 1950 por crise econômica e cambial. Perón, sem sustentação das elites, com baixo êxito na parte econômica e isolado internacionalmente, com poucos sucessos em suas gestões de se aproximar do Brasil, seria crescentemente criticado (Rapoport, 2000: 361-267).

Em 1955, Perón é deposto em um golpe de Estado (Revolución Libertadora) e a política econômica peronista é revista. Abriu-se a economia ao capital estrangeiro e incentivou-se o setor agropecuário. Em verdade, aprofundava-se a liberalização da economia iniciada no final do governo Perón, porém sem o conteúdo retórico nacionalista (Moniz Bandeira, 2010: 266; Ferrer, 2006). O projeto de industrialização promovido por Perón, portanto, pouco avançou. Ao contrário do que ocorria no Brasil, onde as rupturas institucionais não geravam distúrbios mais graves ao processo de industrialização, o desenvolvimento industrial argentino foi seriamente afetado pelas trocas de governo, em um cenário no qual a oposição entre indústria e agroexportadora parecia instransponível (Ferrer, 2006).

O período da Revolución Libertadora, entre 1955-1958, consistiu em uma verdadeira ditadura militar que visava acabar com o peronismo. A Argentina passou a alinhar-se com os EUA, ingressando plenamente no sistema multilateral de Bretton Woods. A exclusão de Perón ajudava a aproximação com o Brasil, porém, a luta contra o peronismo gerou impasses entre a Argentina e os demais países da América do Sul. A presença de Perón como asilado no Paraguai e, posteriormente, na Venezuela resultou em aumento nas animosidades regionais. Romperam-se as relações entre Argentina e Venezuela, após um atentado contra Perón, em Caracas, e os militares argentinos incentivavam operações nas fronteiras do Paraguai, sob o pretexto de combater guerrilhas peronistas ou comunistas que atacariam o território argentino. A relação pouco amistosa da Argentina com o Paraguai promoveria os entendimentos do país guarani com o Brasil (Moniz Bandeira, 2010; Rapoport, 2000).

No governo Vargas, evidencia-se que a falta de coordenação entre Brasil e Argentina não é consequência somente da personalidade dos presidentes. Mesmo com ambos os governantes ligados ao movimento dos trabalhadores e sem uma desconfiança ideológica mútua, permaneciam as resistências devido, em parte, às iniciati-

14 Em verdade, a proposta original apresentada por Vargas era de uma empresa de capital misto; a proposta de uma empresa completamente estatal surgiu de pressão da UDN, partido liberal-conservador, mas apoiado nas classes urbanas. 
vas de Perón para a América do Sul e, em parte, à estratégia de aproximação com os Estados Unidos, na qual a aproximação com governos ideologicamente suspeitos poderia atrapalhar a cooperação militar ou a cooperação para o desenvolvimento (Moniz Bandeira, 2010: 262-270).

\subsection{O governo Kubitschek}

No Brasil, após o interregno Café Filho, assumiria Juscelino Kubitschek (JK), após um período de crise institucional ${ }^{15}$. $\mathrm{JK}$ procuraria dar prosseguimento ao desenvolvimento industrial brasileiro e, ao mesmo tempo, fortalecer a aliança com os Estados Unidos. O governo JK caracterizar-se-ia por forte crescimento alavancado pela indústria, intervenção estatal no processo de desenvolvimento econômico e alta participação do financiamento externo, principalmente americano, nos investimentos produtivos (Giambiagi, 2011; Silva, 1992).

A política externa de $\mathrm{JK}$ deu prosseguimento ao alinhamento políticoestratégico aos EUA, como se evidenciou pela cessão de Fernando de Noronha como base para rastreamento de foguetes. A novidade maior da política exterior restava no âmbito econômico, pois a estratégia de desenvolvimento estabelecida pelo Plano de Metas necessitava de grande volume de capitais dos quais não dispunha o Brasil ${ }^{16}$. O Plano de Metas visava acabar ou diminuir os gargalos de infraestrutura que impediam o desenvolvimento econômico brasileiro. Suas cinco metas (transporte, energia, indústria de base, educação e alimentação) foram em grande medida definidas a partir dos estudos da CMBEU e do grupo BNDE-Cepal. $\mathrm{Ku}-$ bitschek buscou negociar com os Estados Unidos maiores recursos para dar prosseguimento ao plano. Sua maior iniciativa diplomática seria conhecida como a Operação Pan-Americana (OPA) (Silva, 1992).

A OPA refletia a busca do desenvolvimento nacional como parte e resultado de uma cooperação hemisférica mais ampla. Estabelecia o argumento de que a melhor forma de combater ideologias antidemocráticas, como o comunismo, seria por meio do desenvolvimento ${ }^{17}$.

A OPA foi apoiada pela Argentina, comandada desde 1958 por Arturo Frondizi, assim como por outros Estados latino-americanos ${ }^{18}$. A OPA representou uma leve mudança na forma de negociar por recursos pelo desenvolvimento com os EUA: antes feita de modo bilateral, agora englobava o conjunto de países da América Latina. Nesse sentido, a proposta também elevou o prestígio do país ao reforçar sua condição de país latino-americano e solidário com os anseios dos países em desenvolvimento (Silva, 1992; Cervo \& Bueno, 2002).

Os EUA receberam friamente a proposta da OPA e atuaram para esvaziar seu apelo aos países latino-americanos. Esforçaram-se para que as discussões sobre de-

15 JK assumiu após o episódio de golpe e contra-golpe conhecido como Novembrada.

16 O fracasso das negociações com o FMI, em 1959, não pode ser superestimado. Parte da literatura — ver Moniz Bandeira (2010: 284) e Cervo \& Bueno (2002: 297)— designa o momento como ruptura, quando o Brasil havia simplesmente deixado de prosseguir com o programa acordado com o FMI, mas não constrangeu o interesse do capital estrangeiro, ver: Abreu (2013: 220).

17 A proposta foi formulada após a desastrosa viagem de 1958 do vice-presidente Nixon a países da América Latina em que não conseguiu completar todo o roteiro de visitas devido ao modo como foi hostilizado pela população local no Peru e na Venezuela.

18 Paraguai, Chile, Honduras, Venezuela, Peru, Colômbia, Equador 
senvolvimento econômico se mantivessem restritas à OEA, sem a contribuição da Cepal, além de não apresentarem nenhum comprometimento político de ajuda financeira para combater o subdesenvolvimento. No mais, os EUA deram prosseguimento a medidas de ajuda financeira que já estavam sendo gestadas no interior da administração Eisenhower, como a criação de uma instituição financeira interamericana, que levaria à fundação do Banco Interamericano de Desenvolvimento (BID), e aumento das capacidades de financiamento do Eximbank e do Development Fund Bank (Silva, 1992).

Ainda assim, o projeto de investimentos concebido no Plano de Metas seria benéfico aos interesses do empresariado norte-americano (Caputo \& Melo, 2009: 513-538). As empresas transnacionais teriam grandes incentivos para instalarem-se no país com a facilidade de importar bens de capital sem cobertura cambial ${ }^{19}$, com uma série de isenções fiscais e garantias de mercado. Os pesados investimentos públicos em infraestrutura forneciam subsídios necessários para estimular a demanda por bens industrializados. Durante o governo JK, os investimentos estrangeiros no Brasil cresceriam substancialmente, praticamente dobrando de valor entre 1955 e 1956 e mantendo-se elevados até 1963 (Giambiagi, 2011; Caputo \& Melo, 2009).

O interesse pela OPA revela o engajamento entre Brasil e Argentina. Os presidentes coincidiam sobre a necessidade de desenvolvimento econômico por meio do fortalecimento da indústria e do comércio, mesmo com a oposição norte-americana (Saraiva, 2012). Ademais, já havia um pensamento em favor da integração regional e entendimento, consubstanciado nos trabalhos da Cepal e pelo Instituto Superior de Estudos Brasileiros (ISEB), que promovia a aproximação conjunta (Jaguaribe, 2013 [1958]; Halperin, 2010: 55-76; Teixeira da Silva, 2014: 129-132). A cordialidade entre Brasil e Argentina não seria capaz, contudo, de gerar medidas práticas para solucionar problemas comuns. $\mathrm{O}$ apoio de Frondizi à iniciativa foi inclusive criticado por políticos da oposição, que o identificavam como submissão aos interesses brasileiros (Saraiva, 2012; Spektor, 2002).

A aproximação abriu o caminho para a criação da Associação LatinoAmericana de Livre Comércio (ALALC), em 1960, mas a ambiciosa agenda integradora dessa organização acabou exaurida. A proposta da ALALC foi influenciada tanto pelo processo integrador da Europa quanto pelos estudos no seio da Cepal, que advogava o incremento das trocas comerciais na região como maneira de contrabalançar a tendência à deterioração dos termos de troca da região. A ALALC procurava o estabelecimento de uma zona de livre-comércio entre os onze signatários em um prazo de doze anos. Tratava-se de um prazo muito rígido, o que prejudicava a consecução das metas estabelecidas (Prazeres, 2006).

Brasil e Argentina apresentavam interesses convergentes na ALALC, ao advogarem tão somente pela liberalização comercial da América Latina; ainda assim, as duas grandes economias sul-americanas não mantinham efetivo comprometimento com os objetivos de diminuição das tarifas aduaneiras (Prazeres, 2006).

O governo Kubitschek daria continuidade ao processo de aproximação com o governo do Paraguai de Stroessner, inclusive por meio da construção de rodovias que ligariam o território paraguaio ao brasileiro. O apoio brasileiro a Stroessner,

19 Permitida pela instrução 113 da SUMOC. 
que se afastara da Argentina, prejudicaria inclusive visita agendada por JK à Buenos Aires e comprometeria os interesses dos militares argentinos no país guarani. $\mathrm{O}$ Paraguai conseguira um porto franco no Brasil, o Paranaguá, e construía a Ponte da Amizade que possibilitaria maiores possibilidades de escoamento (Moniz Bandeira, 2010: 279-283; Doratioto, 2014).

Com a Bolívia, destacam-se os acordos de Roboré, de 1958, que dariam viabilidade à exploração de hidrocarbonetos e à circulação de mercadorias bolivianas. Desde 1956, ampliava-se o acesso da Bolívia aos portos brasileiros por meio da ferrovia Santa Cruz de la Sierra-Corumbá, diminuindo a dependência boliviana de Buenos Aires (Doratioto, 2014).

A aproximação do Brasil aos governos mediterrâneos revela os limites da aproximação com a Argentina, na medida em que o Brasil sustentava econômica e politicamente o Paraguai, e dava uma opção para o escoamento dos produtos bolivianos e paraguaios (Moniz Bandeira, 2010: 279-285; Doratioto, 2014: 131-133). O plano de comunicações com os países mediterrâneos, nesse sentido, reflete os desígnios de Travassos.

No processo amplo de industrialização por substituição de importações, o Plano de Metas representou um salto qualitativo no que se refere ao parque industrial brasileiro. O país passou a possuir uma matriz industrial diversificada com produção em todos os ramos industriais da economia moderna. Enquanto, no passado, o crescimento industrial vinha especialmente da produção de bens de consumo não duráveis, a produção começava agora a ser liderada pelos bens de capital (aumentando de 5,2\% em 1949 para 11,1\% em 1959 do total da indústria), de consumo duráveis (de 2,5\% para 5\%) e de bens intermediários (de 30,4\% para 37,3\%) (Abreu, 2013: 217).

O Plano de Metas também se caracterizou por dar continuidade ao processo de integração do território brasileiro, com concentração da estrutura produtiva no Sudeste brasileiro, em especial em São Paulo. Os investimentos em transporte, especialmente rodoviários, fortaleceram o combate à estrutura de produção em "arquipélagos" (Becker \& Egler, 1994; Couto e Silva, 1981), em regiões produtivas que não se comunicavam entre si e que direcionavam sua produção ao mercado externo.

A integração econômica do território representou uma efetiva ocupação do interior do país, de maneira dirigida e estimulada pelas autoridades brasileiras. A ocupação do Oeste brasileiro era incentivada desde o primeiro governo Vargas (19301945), com a campanha da Marcha para o Oeste, mas alcançou o ápice no governo $\mathrm{JK}^{20}$, com a construção da nova capital federal, Brasília, e a construção das rodovias que a ligariam às demais regiões do país. O Oeste teria papel central na produção agropecuária para subsidiar a produção industrial do Sudeste, além de absorver parte dos excedentes populacionais que pressionavam as grandes metrópoles brasileiras. A ocupação do interior do território teria também sentido estratégico na proteção das fronteiras com vizinhos, como enfatizava Travassos.

Segundo Vieira (2008), o plano rodoviário seguido por Vargas e continuado por Kubitschek possui clara referência ao pensamento geopolítico de Travassos, voltado para o interior da América do Sul, para a integração das diferentes regiões brasi-

20 Dutra também manteve projetos de integração e valorização territorial, mas em escala menor. 
leiras e para o aumento da influência nos Estados mediterrâneos da América do Sul.

A abertura da rodovia Belém-Brasília daria seguimento aos projetos de revalorização e ocupação da Amazônia, iniciados no segundo governo Vargas, quando da criação da Superintendência da Valorização Econômica da Amazônia (SPVEA) em 1953. Ao longo da década de 1950, a Amazônia seria alvo de políticas de dinamização estimuladas pelo Estado, como a imigração de nordestinos e a disponibilidade de créditos para projetos agropecuários e industriais por meio do Banco de Crédito da Amazônia (Marques, 2013). Essas políticas seriam fortalecidas e ampliadas a partir dos governos militares (Becker, 2004).

$\mathrm{O}$ mandato de Juscelino Kubitschek marca ainda um período de forte crescimento econômico que se mantém até 1962 , durante o qual o país cresceu cerca de $8 \%$ a.a., com destaque para o triênio de 1958 a 1960, quando cresceu a uma média de $10 \%$ a.a. em valores reais. O processo inflacionário, contudo, acelerava-se (Giambiagi, 2011).

\subsection{Os governos Quadros e Goulart}

O aumento do custo de vida e os gastos do governo Kubitschek gerariam impactos que se sentiriam nas eleições de 1960, quando Jânio Quadros, apoiado pela conservadora UDN, foi eleito.

Quadros daria início a um novo conceito de política exterior no país, conhecida como Política Externa Independente (PEI), que vigoraria até o golpe de 1964. A PEI consistia na busca de diversificação de parcerias para atender à crescente oferta industrial brasileira. O governo observava a conveniência de mudar o perfil da inserção brasileira para ganhar maior escala de produção a partir dos investimentos realizados nos anos anteriores. A PEI partia do princípio de que a diversificação das relações exteriores aumentaria os recursos de poder do país ao garantir maior poder de barganha (Cruz, 1989; Ligiero, 2011).

Ademais, a situação econômica do país era delicada, com crescente inflação, déficit fiscal e dívida externa. Como político conservador, Jânio Quadros promoveu uma política econômica ortodoxa, em consonância com os anseios dos investidores estrangeiros e aceita pelos EUA ${ }^{21}$ — conseguindo, inclusive negociar empréstimos com o FMI e com os credores norte-americanos - ao passo que, externamente, procurava uma política externa mais autônoma.

Em artigo para a Foreign Affairs Quadros (1961) afirmava que não questiona a identidade ocidental, cristã e democrática brasileira, mas que o país não faz parte de bloco algum, "nem do bloco neutralista", e reivindicava a liberdade para tomar as decisões necessárias em consonância com o pacifismo brasileiro. Nesse novo perfil, incluía-se a aproximação do Brasil com os países do Terceiro Mundo, como a América Latina, como já vinha ocorrendo durante o governo Kubitschek, e a África que passava pelas guerras de libertação nacional. Ademais, a questão cubana abria fissuras ao sistema interamericano, o que era interpretada por Quadros

21 Destaque para a reforma cambial consolidada pela Instrução 204 da SUMOC, em que se unificava as diversas taxas de câmbio, pondo fim ao "confisco cambial". 
como a possibilidade de maior autonomia para inserir-se internacionalmente e formular modelo próprio de desenvolvimento.

Internamente, no Itamaraty, surgiam diversas expressões de defesa de uma política exterior mais autônoma frente às frustações diplomáticas com que se avolumavam desde a Missão Abbink até a OPA. Os idealizadores da PEI percebiam que não havia elemento de barganha no discurso diplomático da OPA (Cruz, 1989; Dantas, 2011 [1963]), visto que o governo brasileiro enfatizava o alinhamento com o Bloco Ocidental como elemento primordial da política externa, sem alternativa concreta.

Mesmo com o começo da Aliança para o Progresso, lançado pelo governo Kennedy, o impulso por mudanças na condução da política externa brasileira mantevese entre 1961 e 1964. Inclusive, a atuação da Aliança para o Progresso como programa unilateral dos Estados Unidos geraria, posteriormente, reações contra os parâmetros de desenvolvimento definidos no exterior (Dantas, 2011 [1963]: 10).

No curto período do governo Quadros, de janeiro até agosto de 1961, impactouse decisivamente a história da política externa brasileira. O discurso diplomático do governo buscou reforçar o neutralismo, a autodeterminação dos povos e o pacifismo como princípios basilares da política externa brasileira. Nos poucos meses de governo, Quadros realizou uma série de atos de profundo impacto simbólico, como o recebimento de missões comerciais chinesas e soviéticas, a defesa pública da descolonização, a crítica à invasão da Baía dos Porcos, a condecoração de Che Guevara com a Ordem do Cruzeiro do Sul (que geraria fortes críticas por parte da imprensa conservadora) e o encontro de Uruguaiana com o presidente argentino Frondizi (Ligiero, 2011: 35, 105-111).

Em Uruguaiana, os dois presidentes assinaram uma série de acordos que estabeleciam um sistema de consultas e trocas de informações, de apoio à integração, de cooperação pela democracia e contra interferências às soberanias nacionais (Spektor, 2002: 117-145). Os acordos de Uruguaiana voltavam-se para a construção de confianças -inclusive com a retirada de tropas da fronteira e o desenvolvimento tecnológico conjunto (Saraiva, 2012)-.

Em agosto de 1961, houve a renúncia de Jânio Quadros. Provavelmente, Jânio Quadros ressentia-se das crescentes críticas contra seu governo e procurou um blefe político para voltar fortalecido.

A renúncia foi aceita pelo Congresso e a posse de João Goulart foi garantida após uma grave crise política, por meio de um comprometimento de Goulart em assumir com poderes reduzidos, sob um sistema parlamentarista.

Apesar da grave instabilidade política, a PEI manteve-se como paradigma de política externa, como ferramenta de apoio ao desenvolvimento industrial brasilei$\mathrm{ro}^{22}$. Aumentaram-se os contatos comerciais e diplomáticos com a África e com os países do Leste, inclusive com o restabelecimento de relações diplomáticas com a URSS. A política de aproximação com a Argentina foi mantida. Santiago Dantas, chanceler brasileiro entre 1961 e 1962, acreditava que Brasil e Argentina deveriam formar um mercado comum que serviria de base para um mercado latino-

22 O discurso da PEI do período Goulart é sintetizado no discurso dos 3Ds proferido pelo embaixador Araújo Castro, na XVIII sessão da Assembleia Geral da ONU, em que se defende a descolonização, o desarmamento e o desenvolvimento como os princípios básico da atuação internacional brasileira. 
americano integrado (Silva, 1995: 112-113; Cruz, 1989), dando continuidade, pelo menos na retórica, ao projeto iniciado pela ALALC.

As boas relações entre Brasil e Argentina tornaram-se explícitas na Conferência Interamericana de Punta del Este de 1962, em que Brasil e Argentina, apoiados por México, Equador, Chile e Bolívia, foram contra o projeto americano de isolar Cuba do sistema interamericano. Da mesma forma, os seis países se abstiveram da votação que suspenderia Cuba da OEA.

Moniz Bandeira (2010: 329-375) identifica o episódio da questão cubana no âmbito da OEA como um ponto de inflexão na política externa americana com relação aos países da América do Sul. Os EUA, em combinação com elementos civis e militares nos países sul-americanos, aumentaram suas articulações no sentido de pressionar por mudanças que estivessem de acordos com os objetivos de política externa americana. Verifica-se o empenho em não sustentar econômica ou politicamente tais países, com o objetivo de desmoralizar os governos civis.

Em diversos países da América do Sul, as polarizações internas começaram a gerar graves crises políticas, em particular nos países que se abstiveram da votação na OEA. A Aliança para o Progresso, que procurava o desenvolvimento econômico dos países latino-americanos e a estabilidade do governo, por meio do combate a grupos revolucionários de esquerda, tornou-se crescentemente voltada para esse segundo objetivo, em detrimento do primeiro, auxiliando a ascensão dos militares ao poder, considerados um segmento mais organizado e diligente na contrainsurreição (Moreira et al., 2010: 237-261).

A questão cubana revela o afastamento de Brasília com relação a Washington. Apesar de a política externa de Goulart não ter realizado tantos atos chamativos como o governo Quadros, a inclinação ideológica do governante gerava mais desconfianças (Cruz, 1989). A missão de negociação de empréstimos dos Estados Unidos necessários para a consecução do Plano Trienal de estabilização econômica voltou malsucedida. A política econômica — voltada para a recomposição dos salários e para a manutenção da capacidade de investimento estatal—, o reformismo e as nacionalizações de empresas americanas no Rio Grande do Sul geraram desconfianças quanto ao matiz ideológico do governante e à segurança dos investimentos estrangeiros no Brasil. O país permaneceu em uma situação de deterioração do quadro econômico, com aumento da inflação e baixo nível de crescimento econômico, principalmente em 1963, quando o país praticamente estagnou.

Da mesma forma, a independência do Brasil com relação à política externa americana verifica-se ainda na esfera militar; em visita de Goulart a Washington, Kennedy ressaltou que a assistência militar dos EUA ocorria com o objetivo de providenciar às Forças Armadas brasileiras os meios de conter a subversão comunista, contribuir para a defesa coletiva e promover o desenvolvimento econômico. Esse conceito foi rejeitado por Goulart, que o considerava uma interferência na soberania de outros Estados. O Brasil foi ainda contra a criação do Colégio Interamericano de Defesa, visto que poderia estimular a intervenção em assuntos internos de outros Estados. A busca de maior independência do Brasil com relação a Washington demonstra os limites do modelo de inserção internacional americanista, a partir do momento em que o Brasil crescia e buscava outros mercados e novas oportunidades no cenário internacional (Cervo \& Bueno, 2002: 290-307). Essa limitação já era prevista por Travassos. 
Setores conservadores da sociedade brasileira aumentavam crescentemente a oposição ao governo Goulart. Muitos viam o afastamento com relação aos Estados Unidos e a relativa aproximação com Cuba como um erro estratégico que poderia afetar a vinda de capitais americanos e prejudicar o apoio militar estadunidense. A propagação de ideias oposicionistas em think tanks, como o Instituto Brasileiro de Ação Democrática (IBAD) e o Instituto de Pesquisas e Estudos Sociais (IPES), na imprensa conservadora ou por militares provindos da Escola Superior de Guerra ou do Clube Militar era estimulada por empresários e órgãos do governo estadunidense, a partir de uma estratégia de intervenção indireta nos países, menos impopular do que o modelo de intervenção direta da década de 1950 (Fernandes, 2009: 831856; Teixeira da Silva, 2014: 134-138).

Da mesma forma, na Argentina também crescia a oposição contra o governo de Frondizi. Apesar da política externa mais altiva, a autoridade do presidente argentino enfrentava forte resistência por parte dos militares que se mantinham próximos ao poder desde a Revolución Libertadora de 1955.

A debilidade de Frondizi manifestava-se na contínua empreitada de alguns militares, à revelia do presidente argentino, contra o governo paraguaio. Esses militares continuavam a apoiar guerrilhas contrárias ao ditador paraguaio, sob o pretexto de afastar a ameaça do peronismo do entorno regional. Em verdade, os militares argentinos estavam descontentes com a aproximação de Stroessner com o Brasil, e a ameaça de perda do espaço econômico paraguaio, dependente do porto de Buenos Aires para o escoamento de sua produção. Da mesma forma, militares argentinos já haviam incentivado grupos armados de direita na Bolívia, onde a perspectiva de aumento da presença econômica brasileira se evidenciava com a construção da ferrovia entre Santa Cruz de la Sierra e Corumbá e os acordos de Roboré. Em contrapartida, o Brasil sustentava o governo Stroessner, devido a interesses econômicos, em meio a pressões de setores liberais e de esquerda paraguaia contra a ditadura (Moniz Bandeira, 2010: 179-197).

$\mathrm{Na}$ esfera econômica, Frondizi obteve pouco êxito no seu intuito industrializante, aceitando as negociações com o FMI para estabilizar a economia com planos de austeridade, o que minou sua popularidade (Ferrer, 2006). Ademais, mesmo com a aproximação com o Brasil, o então mandatário argentino temia que maior integração econômica pudesse relegar a Argentina a um pessoal secundário na divisão regional do trabalho, receio esse que se manteve entre a elite argentina até o final do século XX pelo menos (Russell \& Tokatlian, 2003; Candeas, 2010).

O fracasso de Frondizi em promover a industrialização argentina em moldes semelhantes ao processo de industrialização por substituição de importações revela a profunda divisão na sociedade e no establishment argentino sobre o tema desde o primeiro governo peronista, o que não ocorreu de forma semelhante no Brasil (Sikkink, 1991). Essa inconsistência da política argentina aliada ao forte crescimento brasileiro, o qual se estenderia até o final da Ditadura Militar, afetou as relações de poder bilateral claramente em favor do Brasil.

Essa inconsistência de política econômica expressava-se também como uma crise de paradigmas quanto à inserção externa da Argentina que se desenrolaria constantemente entre a década de 1930 até o final da Guerra Fria. As elites argentinas tinham dificuldade em definir o papel do país desde o declínio do Reino Unido e o isolamento frente aos Estados Unidos ao passo que as desconfianças mútuas entre 
Brasil e Argentina, dificultavam a adoção de nova estratégia na política internacional (Russell \& Tokatlian, 2003).

Em 1962, influenciados pela posição de Frondizi na Conferência de Punta del Este, os militares argentinos realizaram novo golpe de Estado, depondo o presidente. Os novos mandatários argentinos não estariam de acordo com a posição neutralista, considerada contrária à tradição ocidentalista da Argentina, ou com o nacional-desenvolvimentismo defendido por Frondizi. Assim, as provisões dos acordos de Uruguaiana não prosperariam. Saraiva (2012: 45) destaca ainda que a maioria do congresso argentino era avessa a uma aproximação com o Brasil, devido aos receios de perda de hegemonia na região.

Na presidência Guido, a Argentina aceitaria o pedido do presidente Kennedy de enviar destroieres e aviões para ajudar a bloquear a ilha cubana, em meio à crise dos mísseis. O governo Goulart, contrário à política de alinhamento defendida por Guido, rejeita o mesmo pedido (Spektor, 2002: 117-145). A política externa argentina, agora em completa sintonia com os desígnios americanos, começa a afastar-se do Brasil.

Em 1964, o governo Goulart seria deposto por um movimento militar apoiado por setores conservadores da sociedade civil, dando fim à República Liberal.

\section{Conclusão}

Ao longo da República Nova (1945-1964) verifica-se a continuidade de certas tendências com relação à política interna e externa brasileiras, que, em parte, são consistentes com os desígnios e os desafios apontados por Travassos.

O país procurava desenvolver-se por meio da industrialização por substituição de importações e visa principalmente os capitais norte-americanos e, crescentemente, europeus para esse fim. As políticas mais ambiciosas de captação de recursos estadunidense (Missão Abbink, CMBEU e OPA), contudo, não corresponderam às expectativas, e os sucessivos governos buscaram alternativas, seja pela adoção de políticas internas nacionalistas, como as intervenções no câmbio ou na criação de novas empresas estatais, seja por novos contatos internacionais, como o maior engajamento com a Europa e com a América Latina e, posteriormente, com a África e a Ásia. Como afirmava Travassos, não havia como contestar o poder americano no começo do século XX, mas, à medida que o Brasil se desenvolvia, poderia procurar alternativas, que, gradualmente e inevitavelmente, contrairia os interesses norteamericanos.

Ademais, o Brasil expandia progressivamente sua comunicação com o interior do país, com a abertura de rodovias e de assentamentos no oeste brasileiro, com a criação de Brasília, com as progressivas gestões sobre o território amazônico, vide a criação da SPVEA e a abertura da rodovia Belém-Brasília. O Brasil expandia-se também para o interior da América do Sul, e, mais especificamente, para os países mediterrâneos, por meio da permissão do acesso do Paraguai ao porto de Paranaguá e à construção da Ponte da Amizade e por meio da construção da ferrovia Corumbá-Santa Cruz de la Sierra e dos Acordos de Roboré, de 1958. O progressivo controle do interior do país, em direção ao Paraguai e à Bolívia, e em detrimento da Argentina consistia em dos principais vetores da política pensada por Travassos para se conquistar maior projeção na América do Sul. 
Os interesses comerciais e de investimento entre Brasil e Argentina, os principais países da região, não eram necessariamente contrários. Havia uma clara complementação comercial entre os produtos agrícolas ofertados por cada país e uma efetiva oportunidade de complementação industrial, via acesso a mercados e a insumos industriais. Além do mais, as altas taxas de crescimento brasileiro poderiam ser vistas como uma oportunidade para acesso ao mercado brasileiro ou como fonte de recursos para a Argentina. Essa capacidade de maior coordenação entre os dois países foi efetivamente percebida por estadistas, como Perón, Frondizi, JK, Quadros e Goulart, e por teóricos no âmbito da Cepal e do Iseb. No entanto, as iniciativas de parte a parte eram vistas com desconfiança.

A reedição do Pacto $A B C$, proposta por Perón, gerou animosidades contra o mandatário argentino por parte das elites civis e militares. Nesse caso, a posição neutralista da argentina, em momento de plena Guerra Fria, e com a posição de alinhamento brasileiro com relação à Washington prejudicou o entendimento, enquanto as gestões de Perón por uma união econômica na América do Sul eram vistas mais como uma ameaça geopolítica do que como uma oportunidade.

A aproximação entre Frondizi e JK e, posteriormente, com Quadros enfrentou uma série de limitações. A ALALC perdeu relevância como vertente da política externa ou como instrumento de política comercial e econômica, sendo de pouca eficácia. O apoio do Brasil ao Paraguai e à Bolívia foi motivo de atrito entre os dois países, particularmente, na percepção dos militares argentinos que se mostravam desconfiados das intenções brasileiras e ressentiam a perda de influência sobre os países mediterrâneos. A permanência de desconfianças entre os dois países, apesar de interesses econômicos complementares e da iniciativa comum de líderes políticos (Candeas, 2010), sugere que a cisão entre os países se mantinha devido a outros fatores, como os geopolíticos relacionados à ascendência sobre os países mediterrâneos.

Nesse sentido, a política externa voltada para a contenção da Argentina e para a ascendência sobre os países mediterrâneos - Paraguai e Bolívia - encontrava-se embasada em pressupostos geopolíticos primeiramente delineados por Maria Travassos, em Projeção continental do Brasil.

O crescimento econômico brasileiro, desse modo, possuía um sentido geopolítico de contenção da estagnante Argentina e de consolidação da hegemonia brasileira sobre a América do Sul.

A relação dos dois países também era afetada pela inserção de cada país no âmbito da Guerra Fria e, particularmente, pelo relacionamento com os Estados Unidos. O Brasil buscava um amplo engajamento com a grande potência, com o objetivo de aprofundar a industrialização, como já havia ocorrido ao longo da Segunda Guerra Mundial, e aplicou progressivamente revisões críticas ao alinhamento, culminando com a PEI. As intervenções militares na política interna brasileira resultaram em algumas reformas, mas não afetariam radicalmente a consistência básica da política externa brasileira ou o projeto de desenvolvimento nacional e integração territorial.

A Argentina, por sua vez, adotou um comportamento errático, no qual a busca por autonomia neutralista (Perón) e a favor da indústria era substituída por uma atitude liberal (Revolución Libertadora), em favor dos interesses da agroexportação, sem um claro consenso sobre qual modelo de desenvolvimento deveria ser seguido. Nessa situação, as ações de um moderado, como Frondizi, eram tratadas com des- 
confiança pelas forças internas do Estado. Da mesma forma, o declínio relativo do Reino Unido, após a Segunda Guerra Mundial, prejudicou o entendimento de como seria a inserção argentina nesse novo contexto, no qual a agroexportação não mais complementava a economia da principal potência à época. A ação externa do país platino, desse modo, era fragilizada, e prejudicava uma coordenação mais efetiva com o Brasil ou com os Estados Unidos.

$\mathrm{O}$ forte crescimento econômico brasileiro no período, aliado à relativa estagnação argentina, resultaria em mudança das relações de poder econômico na região. Tal tendência se verificou de modo contínuo, desde a década de 1930, com o começo da industrialização por substituição de importação até a década de 1980, com o fim do período desenvolvimentista no Brasil. Em 1930, o PIB argentino era o dobro do brasileiro e, em 1980, representava somente um terço. Além disso, o Brasil contaria com uma economia mais diversificada e industrializada, com maior capacidade de mobilização militar e de exercer seus interesses na região (Mello, 2001).

A inserção internacional perseguida pelo Brasil prejudicava o entendimento comum com a Argentina e aumentava a disputa por influência na região. $\mathrm{O}$ crescimento brasileiro era mais visto como uma ameaça do que como uma oportunidade, principalmente por causa do aumento da presença brasileira nos países vizinhos e pela gradativa mudança nas relações de poder na América do Sul, tendentes ao Brasil. Da mesma forma, no Brasil também se via com desconfiança as ações empreendidas pela Argentina - principalmente durante o mandato peronista - de modo que o crescimento de um era observado como perda do outro.

A hipótese inicial, portanto, de que a disputa com a Argentina por preeminência na América do Sul foi fundamental para o baixo nível de coordenação regional e que o modelo de desenvolvimento perseguido pelo Brasil, ao diminuir a influência argentina na região, prejudicava o entendimento entre os dois países e, como consequência, a cooperação em todo o subcontinente, foi confirmada.

Muitas das tendências apresentadas acima - aprofundamento da industrialização, aumento da influência brasileira na América do Sul, aumento da presença do Estado no interior do país, particularmente na Amazônia - seguiriam ao longo do período militar, o que tencionou as relações com a Argentina e progressivamente com os Estados Unidos (Gonçalves \& Miyamoto, 1993).

A busca de preeminência na América do Sul prejudicou, em larga medida, os entendimentos com a Argentina e a possibilidade de uma ação regional coordenada em benefício de ambos os países e da região como um todo, uma vez que não havia razões puramente econômicas que justificassem esse afastamento e essa disputa.

Da mesma forma, as ações traçadas por Mario Travassos foram, em boa medida, seguidas pelo Brasil, ao longo do período analisado, e depois mantidas e aprofundadas, no período subsequente, da Ditadura Militar (1964-1985). Assim, muitos dos preceitos geopolíticos foram confirmados, como a disputa com a Argentina por influência pela Bolívia e Paraguai, a expansão da ação estatal para Amazônia, e a rivalidade emergente com os Estados Unidos.

\section{Referências Bibliográficas}

Abreu, Marcelo de Paiva (2013) "O processo econômico", em A. C. Gomes (ed.) Olhando para dentro. Rio de Janeiro: Objetiva, 217-220. 
Becker, Bertha (2004) Amazônia: Geopolítica na virada do III milênio. Rio de Janeiro: Garamoud.

Becker, Berta K. \& Egler, Cláudio A. G (1994) Brasil: uma nova potência na Economia Mundo. Rio de Janeiro: Bertrand Brasil, $2^{\text {a }}$ ed.

Cairo, Heriberto (2008) "A América Latina no século XXI: geopolítica crítica dos Estados e os movimentos sociais, do conhecimento e da representação". Caderno CRH, vol. 21, núm. 53, 221-237.

Candeas, Alessandro (2010) A integração Brasil-Argentina: história de uma ideia na "visão do outro”. Brasília: FUNAG.

Caputo, Ana Cláudia \& Melo, Hildete Pereira de (2009) “A industrialização brasileira nos anos de 1950: uma análise da instrução 113 da SUMOC”. Estudos Econômicos (São Paulo), vol. 39, núm. 3, 513-538.

Carvalho, José Murilo de (2005) Forças Armadas e política no Brasil. Rio de Janeiro: Jorge Zahar.

Cervo, Amado \& Bueno, Clodoaldo (2002) História da política exterior do Brasil. Brasília: IBRI.

Chiavenato, Julio (1981) Geopolítica, arma do fascismo. São Paulo: Ed. Global.

Cruz, José Humberto de Brito (1989) "Aspectos da evolução da diplomacia brasileira no período da política externa independente (1961-1964)", em Ensaios de História Diplomática do Brasil (1930-1986). Brasília: FUNAG/IPRI, 65-78.

Dantas, Santiago (2011 [1963]) Política Externa Independente. Brasília: FUNAG.

Doratioto, Francisco (2014) O Brasil no Rio Prata (1822-1994). Brasília: FUNAG.

Fernandes, Ananda Simões (2009) “A reformulação da Doutrina de Segurança Nacional pela Escola Superior de Guerra no Brasil: a geopolítica de Golbery do Couto e Silva". Antíteses, vol. 2, núm. 4, 831-856.

Ferrer, Aldo (2006) A economia argentina: de suas origens ao início do século XXI. Rio de Janeiro: Elsevier.

Furtado, Celso (2005) Formação econômica do Brasil. São Paulo: Editora Nacional.

Giambiagi, Fabio (2011) Economia brasileira Contemporânea (1945-2010). Rio de Janeiro: Elsevier.

Gomes, Angela de Castro (1994) A invenção do Trabalhismo. Rio de Janeiro: Relume Dumará, 2 ed.

Gonçalves, Williams \& Miyamoto, Shiguenoli (1993) "Os Militares na Política Externa Brasileira: 1964-1984”. Estudos Históricos (Rio de Janeiro), vol. 6, núm. 12, 211-246.

Guglialmelli, Juan Enrique (1978). Geopolítica del Cono Sur. Buenos Aires: Ed. El Cid.

Halperin, Túlio (2010) “A CEPAL em seu contexto histórico". Revista da CEPAL, número especial em português, 55-76.

Hirst, Monica (2006) "Os cinco «As» das relações Brasil-EUA: aliança, alinhamento, autonomia, ajustamento e afirmação”, em H. Altmani \& A. C. Lessa (ed.) Relações internacionais do Brasil: temas e agendas. São Paulo: Saraiva, 94-97.

Jaguaribe, Helio (2013 [1958]) O nacionalismo na atualidade brasileira. Brasília: FUNAG.

Ligiero, Luiz Fernando (2011) A autonomia na política externa brasileira. Brasília: FUNAG.

Mackinder, Halford (1904) "The Geographical Pivot of History". The Geographical Journal, vol. 23, núm. 4, 421-437.

Malagrida, Carlos Badía (1919) El factor geográfico en la política sudamericana. Madrid: Establecimiento tipográfico de Jaime Ratés. 
Marques, Gilberto, S. (2013) "SPVEA: o Estado na crise do desenvolvimento regional amazônico (1953-1966)”. REVISTA Soc. Bras. Economia Política (São Paulo), núm. 34, 163-198.

Martins, Marcos Antônio Fávaro (2011) Mário Travassos e Carlos Badia Malagrida: dois modelos geopolíticos sobre a América do Sul. Dissertação de Mestrado em Integração da América Latina. Escola de Artes, Ciências e Humanidades, Universidade de São Paulo, São Paulo.

Mello, Leonel Itaussu Almeida (1997) A Geopolítica do Brasil e a Bacia do Prata. Manaus: Ed. da Universidade do Amazonas.

Mello, Leonel Itaussu Almeida (2001) "Brasil e Argentina em perspectiva histórica". Perspectivas (São Paulo), núm. 24/25, 131-143.

Moniz Bandeira, Luiz Alberto (2010) Brasil, Argentina e Estados Unidos: conflito e integração na América do Sul (da Tríplice Aliança ao Mercosul). Rio de Janeiro: Civilização Brasileira.

Moreira, Luis Felipe Viel et al. (2010) As Relações Internacionais da América Latina. Petrópolis: Vozes.

Moura, Gerson (1991) Sucessos e ilusões: Relações internacionais do Brasil durante e após a Segunda Guerra Mundial. Rio de Janeiro: FGV.

Pinheiro, Leticia (2004) Política externa brasileira. Rio de Janeiro: Jorge Zahar.

Prazeres, Tatiana (2006) “A Integração Sul-Americana: uma idéia ainda fora do lugar?”, em O Brasil e a América do Sul: desafios no século XXI. Brasília: Fundação Alexandre de Gusmão / Instituto de Pesquisa de Relações Internacionais, 13-59.

Quadros, Jânio (1961) “Brazil's New Foreign Policy”. Foreign Affairs. [En línea. URL: $<$ http://www.foreignaffairs.com/articles/23339/jÃ cnio-quadros/brazils-new-foreignpolicy>. Consultado dia 20 de setembro de 2016].

Rapoport, Mario (2000) Historia económica, política y social de la Argentina (1880-2000). Córdoba: Macchi.

Ratzel, Friedrich (1897) Politische Geographie. München: R. Oldenbourg

Rodrigues, Lysias (1947) A geopolitica do Brasil. Rio de Janeiro: Ministério da Guerra.

Russell, Roberto \& Tokatlian, Juan Gabriel (2003). "O lugar do Brasil na política externa da Argentina: a visão do outro". Novos estudos, núm. 65, 71-83.

Saraiva, Miriam Gomes (2012) Encontros e desencontros: o lugar da Argentina na política externa brasileira. Belo Horizonte: Fino Traço.

Scenna, Miguel Angel (1975) Argentina-Brasil: Cuatro siglos de rivalidade. Buenos Aires: Ed. La Bastilla.

Shilling, Paulo R. (1981) O expansionismo brasileiro: a Geopolítica do General Golbery e a diplomacia do Itamarati. São Paulo: Ed. Global.

Sikkink, Kathryn (1991) Ideas and institutions: developmentalism in Brazil and Argentina. Ithaca: Cornell University Press.

Silva, Alexandra de Mello e (1992) A política extema de JK: a Operação Pan-Americana. Rio de Janeiro: CPDOC.

Silva, Alexandra de Mello (1995) "O Brasil no continente e no mundo". Estudos históricos (Rio de Janeiro, CPDOC), vol. 8, núm. 15, 112-113.

Silva, Golbery do Couto e (1967) Geopolitica do Brasil. Rio de Janeiro: J. Olympio.

Silva, Golbery do Couto e (1981) Conjuntura política nacional: o Poder Executivo e geopolítica do Brasil. Rio de Janeiro: José Olympio, $3^{\mathrm{a}}$ ed.

Souto, Cíntia Vieira (2014) "A missão militar brasileira de instrução no Paraguai e a aproximação paraguaio brasileira na década de 1940”. XXI Encontro Estadual de História 
ANPUH/RS, Universidade do Vale do Rio dos Sinos, São Leopoldo, Rio Grande do Sul, Brasil.

Spektor, Matias (2002) "O Brasil e a Argentina entre a cordialidade oficial e o projeto de integração: a política externa do governo de Ernesto Geisel (1974-1979)". Revista Brasileira de Política Internacional, vol. 45, núm. 1, 117-145.

Storni, Segundo (2009 [1916]) Intereses argentinos en el mar. Buenos Aires: Armada Argentina. $\quad[$ Em línea. URL: $<$ http://www.edena.mindef.gob.ar/docs/Intereses_Argentinos_en_el_Mar.pdf $>$. Acesso em 18 de setembro de 2016].

Távora, Juarez (1954) Objetivos nacionais permanentes. Rio de Janeiro: ESG.

Teixeira da Silva, Francisco Carlos (2014) "O Brasil no mundo", em D. A. R. Filho (coord.) Modernização, ditadura e democracia. Rio de Janeiro: Objetiva.

Travassos, Mario (1947) Projeção continental do Brasil. São Paulo: Editora Nacional, $4^{\text {a }}$ ed.

Vieira, Frederick Brum (2008) Modelo Travassiano - a geopolítica que guia o Brasil na democracia e na ditadura. São Paulo: Milênio. 